\title{
Effect of Sheet Resistance and Morphology of ITO Thin Films on Polymer Solar Cell Characteristics
}

\author{
Ram Narayan Chauhan, ${ }^{1}$ C. Singh, ${ }^{2}$ R. S. Anand, ${ }^{2}$ and Jitendra Kumar ${ }^{1}$ \\ ${ }^{1}$ Materials Science Programme, Indian Institute of Technology Kanpur, Kanpur 208016, India \\ ${ }^{2}$ Department of Electrical Engineering, Indian Institute of Technology Kanpur, Kanpur 208016, India
}

Correspondence should be addressed to Ram Narayan Chauhan, chauhanramnarayan@gmail.com

Received 8 October 2011; Accepted 21 December 2011

Academic Editor: Bhushan Sopori

Copyright ( 2012 Ram Narayan Chauhan et al. This is an open access article distributed under the Creative Commons Attribution License, which permits unrestricted use, distribution, and reproduction in any medium, provided the original work is properly cited.

\begin{abstract}
Solar cell fabrication on flexible thin plastic sheets needs deposition of transparent conducting anode layers at low temperatures. ITO thin films are deposited on glass by RF sputtering at substrate temperature of $70^{\circ} \mathrm{C}$ and compare their phase, morphology, optical, and electrical properties with commercial ITO. The films contain smaller nanocrystallites in (222) preferred orientation and exhibit comparable optical transmittance $(\sim 95 \%)$ in the wavelength range of $550-650 \mathrm{~nm}$, but high sheet resistance of $\sim$ $103 \Omega / \square$ (the value being $\sim 36 \Omega / \square$ for commercial ITO).The polymer solar cells with PEDOT: PSS and P3HT: PCBM layers realized on RF sputtered vis-a-vis commercial ITO thin films are shown to display a marginal difference in power conversion efficiency, low fill factor, and low open-circuit voltage but increased short-circuit current density. The decrease in fill factor, opencircuit voltage is compensated by increased short-circuit current. Detailed study is made of increased short-circuit current density.
\end{abstract}

\section{Introduction}

Indium tin oxide (ITO) is $n$-type degenerate semiconductor with a wide band gap $\left(E_{g}=3.5-4.2 \mathrm{eV}\right)$. It has excellent photoelectrolytic properties, namely, electrical conductivity $\left(10^{3}-10^{4} \mathrm{ohm}^{-1} \mathrm{~cm}^{-1}\right)$, transparency $(80-95 \%)$ in the visible range and reflectance better than $80 \%$ in the infrared region [1-5]. It has found numerous applications in transparent electrode, antireflection coating, heat reflecting mirror, transparent electromagnetic shield, display, optoelectronic and photovoltaic devices, and so forth [6]. ITO is of particular interest to high efficiency heterojunction solar cells [7] and organic light-emitting diode (OLED) [8, 9]. Its thin films can be prepared by a variety of techniques like plasma-enhanced metal organic chemical vapour deposition (PEMOCVD) [10], ion-assisted deposition (ISD) [11], pulsed laser deposition (PLD) [12-14], dip coating [15], ion beam sputtering [16], RF magnetron sputtering $[17,18]$, and reactive thermal evaporation [19]. However, majority of the methods require elevated substrate temperatures to obtain thin films of reasonably high conductivity and good optical transmittance. But the amorphous silicon photovoltaic and flexible electrooptical devices demand the deposition of ITO at low temperatures $\left(<200^{\circ} \mathrm{C}\right)$. RF sputtering allows preparation at low temperatures and on large areas [20]. Therefore, an attempt has been made here to fabricate solar cells using (i) ITO thin films deposited by RF sputtering and (ii) commercial low sheet resistance ITO and undertake comparative study of their characteristics.

\section{Experimental Details}

ITO thin films of thickness $t \sim 120 \mathrm{~nm}$ were deposited on a glass plate (size $30 \mathrm{~mm} \times 30 \mathrm{~mm}$ ) through shadow mask with $8 \mathrm{~mm}$ wide $\times 30 \mathrm{~mm}$ long slits at substrate temperature of $70^{\circ} \mathrm{C}$ in pure argon by radiofrequency (RF) sputtering using $\mathrm{In}_{2} \mathrm{O}_{3}: \mathrm{SnO}_{2}(90: 10 \mathrm{wt} \%)$ target of $99.99 \%$ purity. The system was evacuated upto $\sim 10^{-6}$ mbar prior to deposition. The film thickness, sheet resistance, and optical transmittance were measured by surface Profilometer (Tencoralpha-step $\mathrm{X}-100$ ), four probe sheet resistance measurement system, and a fiber optic spectrometer (Ocean optic model USB 2000), respectively. The crystalline phase was determined by X-ray diffraction (Thermo Electron ARL X'TRA X-ray 


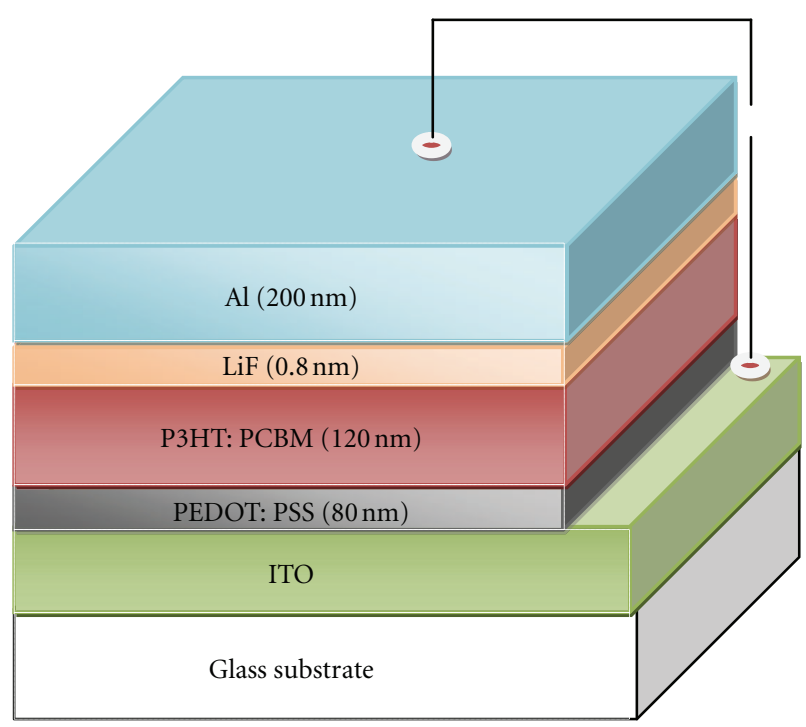

FIgURE 1: Schematic diagram of solar cell device.

diffractometer), whereas the morphology was observed in scanning electron microscopes FEI, (Quanta 200, and carl zeiss SUPRA $40 \mathrm{VP}$ ). Further, the work function of RF sputtered and commercial ITO films was measured by Kelvin probe model 7.

For solar cell fabrication, polyethylenedioxythiophene: polystyrenesulfonic acid (PEDOT: PSS) was spin-coated at $2500 \mathrm{rpm}$ on the patterned ITO-glass substrate and annealed at $120^{\circ} \mathrm{C}$ for $1 \mathrm{~h}$ in vacuum $\sim 1-2 \times 10^{-5} \mathrm{mbar}$. A polymer active layer was then spin-coated at $1100 \mathrm{rpm}$ over the dried PEDOT : PSS layers using the solutions of P3HT (poly 3-hexylthiophene) and PCBM ([6,6]-phenyl-C61-butyric acid methyl ester) $20 \mathrm{mg} / \mathrm{cc}$ each in an organic solvent mixed in volume ration $1: 1$ and annealed at $110^{\circ} \mathrm{C}$ for $20 \mathrm{~min}$ in vacuum. Finally, bilayer metal cathode of $\mathrm{LiF}$ and $\mathrm{Al}$ (thickness $0.8 \mathrm{~nm}$ and $200 \mathrm{~nm}$, resp.) was realized on the active layer by thermal evaporation method. The device structure glass/ITO/PEDOT : PSS/P3HT : PCBM/LiF/Al thus fabricated is shown schematically in Figure 1. Similar devices were also made in the same batch on the commercial ( $36 \mathrm{ohm} / \mathrm{sq}, 150 \mathrm{~nm}$ thickness) ITO coated glass substrates. The $J-V$ characteristics of solar cells were obtained by Keithley source measure unit (SMU) model 236 and a data acquisition system.

\section{Results and Discussion}

The XRD patterns of the commercial and RF-sputtered ITO thin films are shown in Figure 2. The commercial ITO sample exhibits five peaks of indices 211, 222, 400, 440, and 622, which match well with the bixbyite tin substituted $\mathrm{In}_{2} \mathrm{O}_{3}$ structure having lattice parameter $a=10.124 \AA$ [21]. The thermalized sputtered species are known to orient as (222) plane while the species with higher energies prefer growth planes as (400) and (440) [22]. However, RF-sputtered ITO thin films exhibit (222) preferred orientation (Figure 2(b)). Obviously, the glass substrate is either placed in thermalized

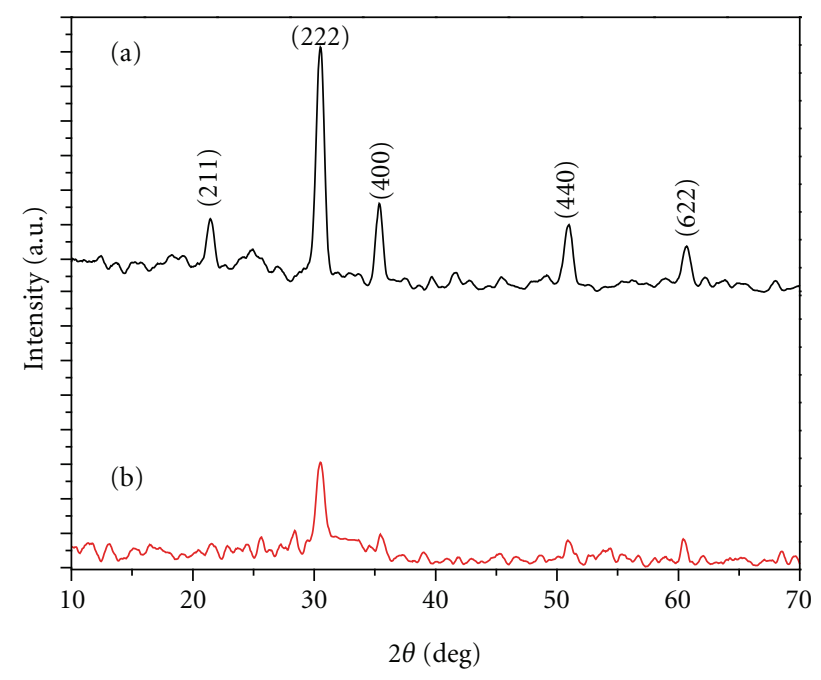

FIGURE 2: XRD patterns of (a) commercial and (b) RF-sputtered ITO thin films.

region or the above observation does not conform to the cited findings [22]. The grain size $(\delta)$ has been deduced with the 222 diffraction peak data and using the Scherrer relation

$$
\delta=\frac{0.9 \lambda}{\beta \cos \theta},
$$

where $\beta$ is the corrected full width at half maxima (FWHM) at Bragg angle $\theta$ and $\lambda$ is the X-ray wavelength [23-25]. The values of $(\delta)$ for the RF-sputtered and commercial ITO samples are $\sim 7$ and $\sim 12 \mathrm{~nm}$, respectively.

The morphologies of the thin films are shown in Figure 3. These reveal granular structure with smaller average grain size $(\sim 7 \mathrm{~nm})$ for RF-sputtered ITO thin films vis-a-vis commercial sample. This is observation consistent with the XRD data and results due to low deposition rate $\left(0.7 \AA s^{-1}\right)$ used $[26,27]$. The optical transmittance spectra of ITO thin films in the wavelength range of $300-800 \mathrm{~nm}$ are shown in Figure 4. Accordingly, the RF sputtered thin films display somewhat poor transmittance than the commercial ITO below $550 \mathrm{~nm}$ and above $650 \mathrm{~nm}$, possibly because of substantial scattering from the grain boundary regions. Nevertheless, transmittance level of ITO thin films prepared by RF sputtering is as high as $95 \%$ in the wavelength range of 550-650 $\mathrm{nm}$.

The sheet resistance $\left(R_{s}\right)$ values of RF sputtered and commercial ITO thin films are 103 and $36 \Omega / \square$, respectively. The values of electrical conductivity $(\sigma)$ of RF and com ITO thin films, obtained from their sheet resistance $\left(R_{s}=1 / \sigma t\right)$ are $8.1 \times 10^{2}$ and $1.9 \times 10^{3} \mathrm{ohm}^{-1}-\mathrm{cm}^{-1}$, respectively. Slater theory tells that smaller grain size will have a higher energy barrier. The carriers have to cross the grain boundary, when they travel from one grain to the other. They need additional energy to surmount the grain boundary barrier [28]. The lower electrical conductivity in RF-sputtered ITO thin film is associated with larger barrier height $\phi \propto(X-f \delta)^{2}$, formed by the smaller grain size $(\delta)$. Here, $X$ is the barrier width 


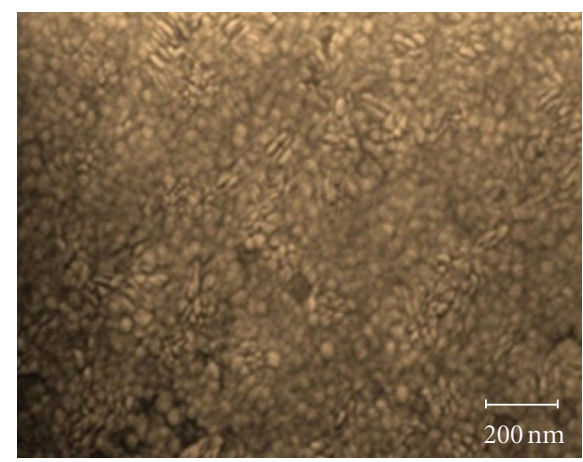

(a)

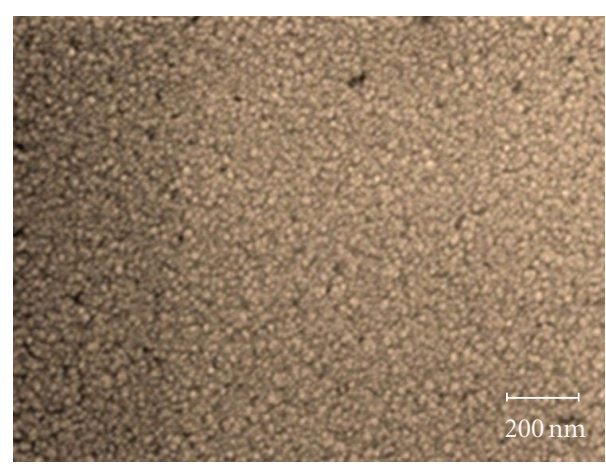

(b)

FIGURE 3: Scanning electron micrographs of (a) commercial and (b) RF-sputtered ITO thin films.

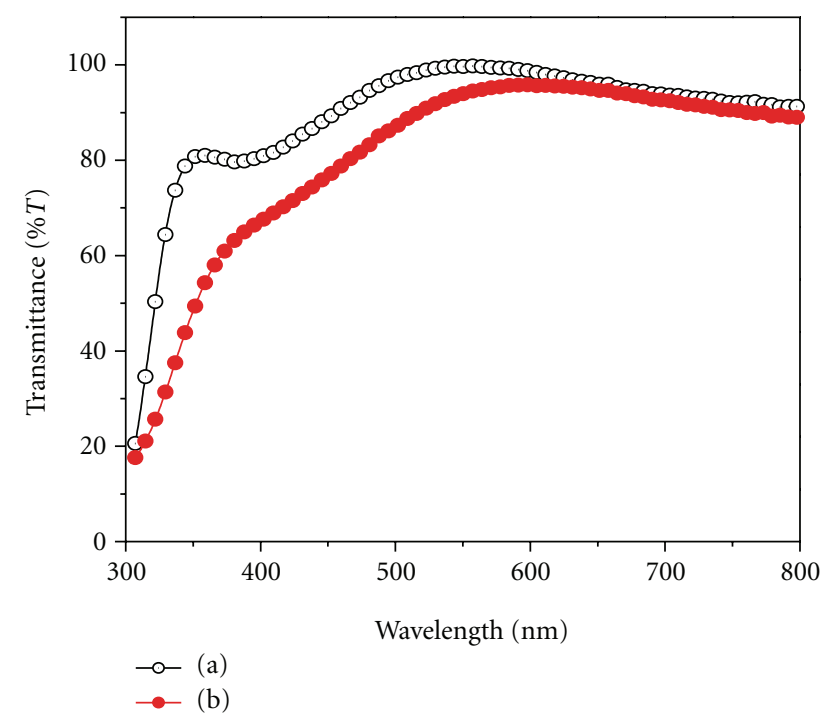

FIgURE 4: Transmission spectra of (a) commercial and (b) RFsputtered ITO thin films.

related to the number of disorder atom layers, and $f$ is a fraction of the order of $1 / 15$ to $1 / 50$.

The solar cells fabricated on the commercial and RFsputtered ITO thin films had areas of 0.05 and $0.08 \mathrm{~cm}^{2}$, respectively. Their $J-V$ characteristics are presented in Figure 5. The fill factor (FF) and conversion efficiency $(\eta)$ are deduced from [29-31]

$$
\begin{gathered}
\mathrm{FF}=\frac{(J V)_{\max }}{J_{\mathrm{sc}} V_{\mathrm{oc}}}=\frac{P_{\max }}{J_{\mathrm{sc}} V_{\mathrm{oc}}}, \\
\% \eta=\frac{P_{\max }}{P_{\mathrm{in}}} \times 100=\frac{\mathrm{FF} \times J_{\mathrm{sc}} V_{\mathrm{oc}}}{P_{\text {in }}} \times 100,
\end{gathered}
$$

where $(J V)_{\max }$ represents the maximum power that can be extracted from the cell and $J_{\mathrm{sc}}, V_{\mathrm{oc}}$, and $P_{\mathrm{in}}$ stand for the short-circuit current density $\left(\mathrm{A} \mathrm{cm}^{-2}\right)$, open-circuit voltage (V) and incident photon flux $\left(\mathrm{W} \mathrm{cm}^{-2}\right)$, respectively. Clearly, solar cell based on RF-sputtered ITO generates more current density $\left(J_{s c} \sim 7.6 \mathrm{~mA} \mathrm{~cm}^{-2}\right)$ due to more light absorption

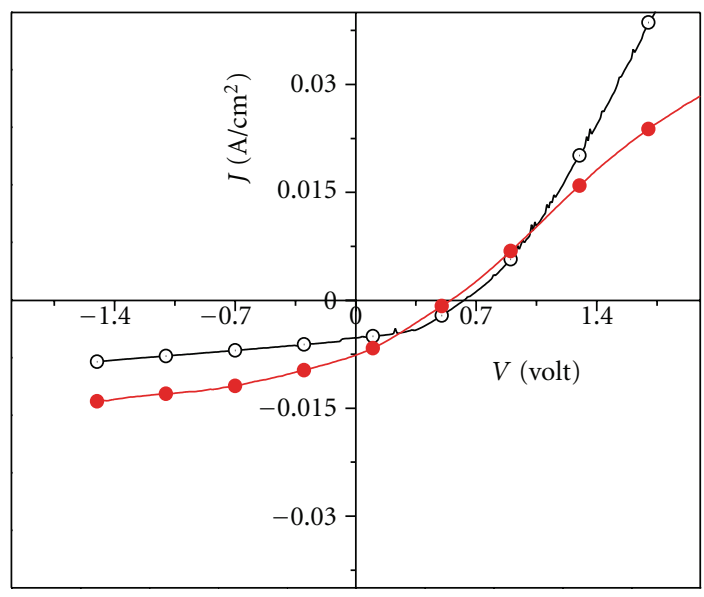

$$
\begin{aligned}
& \multimap-\text { Commercial } \\
& - \text { RF sputtered }
\end{aligned}
$$

Figure 5: Current density $(J)$-voltage $(V)$ characteristics of solar cells on commercial ITO and RF sputtered ITO thin films.

(Figure 6). More light is scattered from the grain boundaries of RF-sputtered ITO, leading to better absorption. The scattering light intensity $\left(I_{g}\right)$ from the grain boundaries is expressed as [32]

$$
I_{g}=I_{0}-\left(1-R_{L}\right) e^{-\gamma_{g} t},
$$

where $I_{0}$ is the intensity of incident light, $\mathrm{R}_{L}$ is reflection loss, $t$ is the thickness of film, and $\gamma_{g}$ is the grain boundary scattering coefficient. Here, the light scattering from the pore has been neglected because of film being compact. The scattering coefficient $\left(\gamma_{g}\right)$ depends on the wavelength $(\lambda)$ of incident light, grain density $\left(N_{g}\right)$, grain size $(\delta)$, absolute refractive index difference $(\Delta n \sim$ refractive index difference of ITO and glass) and is given by

$$
\gamma_{g}=N_{g}\left(\frac{\pi^{3}}{2 \lambda}\right) \delta^{4}(\Delta n)^{2}
$$




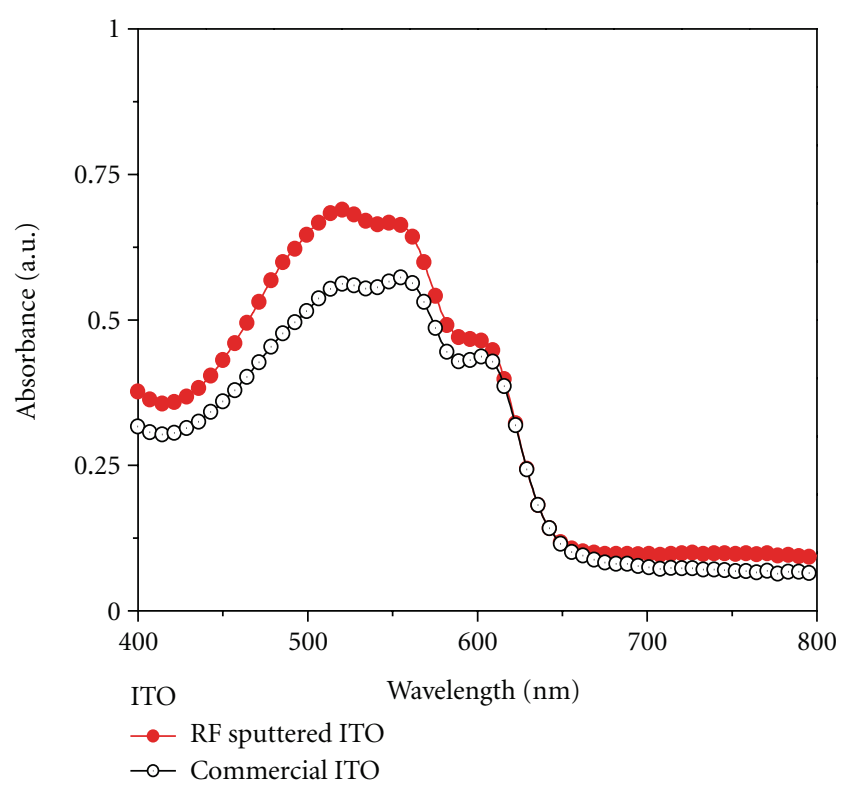

FIgURE 6: Absorption spectra of the devices fabricated on commercial and RF-sputtered ITO thin films.

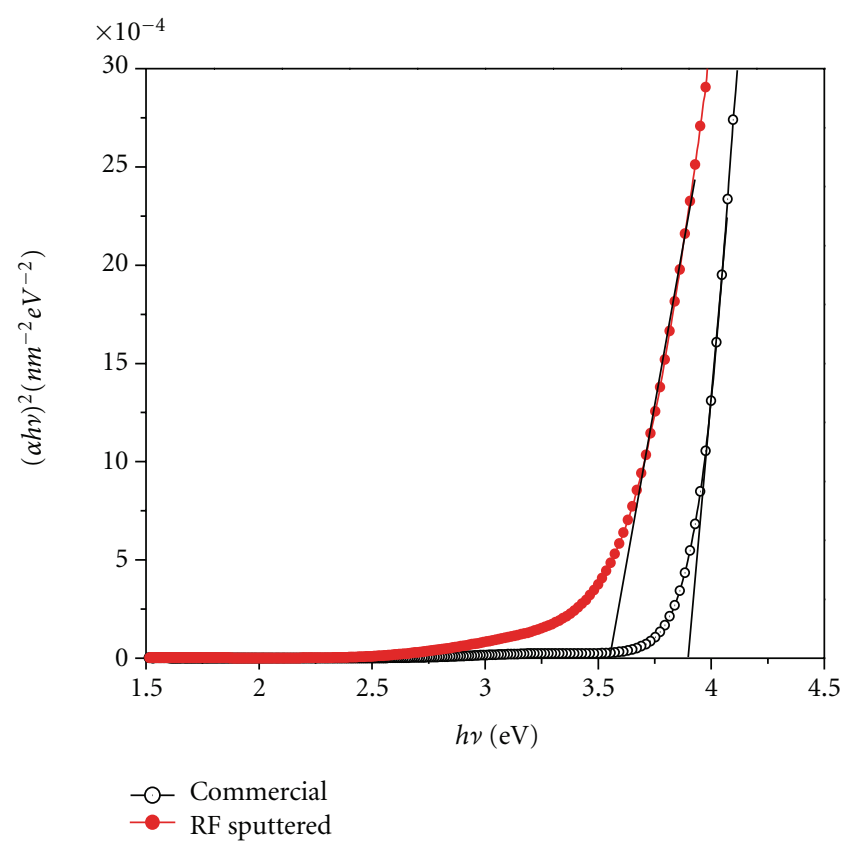

FIGURE 7: $(\alpha h \nu)^{2}$ versus $h v$ plots for commercial and RF-sputtered ITO thin films.

The linear refractive index $(n)$ of thin films can be deduced from [33]

$$
\frac{n^{2}-1}{n^{2}+2}=1-\sqrt{\frac{E_{g}}{20}},
$$

where $E_{g}$ is the energy band gap of the film. The $E_{g}$ of a direct band gap semiconductor can be estimated from the relation [5]

$$
(\alpha h v)^{2}=A\left(h v-E_{g}\right)
$$

where $A$ is a constant, $\alpha$ represents the absorption coefficient, and $h v$ stand for photon energy. The values of the energy band gap of the RF-sputtered and commercial ITO thin films have been determined from the plot $(\alpha h \nu)^{2}$ versus photon energy $(h \nu)$ by extrapolating linear portion of the spectrum to the abscissa ( $h v$-axis) as shown in Figure 7 ; the values obtained are 3.56 and $3.91 \mathrm{eV}$ for RF sputtered and commercial ITO thin films, respectively. Their refractive index values obtained from (6) are 2.26 and 2.19, respectively. The corresponding absolute refractive index difference $(\Delta n)$ values turn out to 0.76 and 0.69 , respectively, by taking the " $n$ " value of glass substrate as 1.5. Since the RF-sputtered films have small grain size, their number density $\left(N_{g}\right)$ will be larger than the commercial ITO samples. So, RF-sputtered ITO films should exhibit larger grain boundary regions hence the more scattered light towards the active layer for enhancing the short-circuit current density.

The values of the open-circuit voltage achieved in devices on commercial and RF-sputtered ITO glass substrate are 0.63 and $0.55 \mathrm{~V}$, respectively. The open-circuit voltage is mainly governed by the junction between two organic materials [34]. The open-circuit voltage $\left(V_{\mathrm{oc}}\right)$ is given by energy difference between the LUMO of acceptor and HOMO of the donor with a reduction of $0.2 \mathrm{~V}$ arising due to band bending at contact following accumulation of charges when the contact is ohmic in nature. However, in case of a nonohmic contact, $V_{\mathrm{oc}}$ is given by the difference of the work functions [35, 36]. The values of work function for the RF-sputtered and commercial ITO measured with Kelvin Probe are $4.76 \pm$ $0.02 \mathrm{eV}$ and $4.84 \pm 0.02 \mathrm{eV}$, respectively. The difference in work function may arise due to size effects and additional defects present in RF-sputtered films vis-a-vis commercial ITO. These features may trap/accumulate charges at the anode interface and cause reduction in the work function. Incidentally, the $V_{\mathrm{oc}}$ of RF-sputtered ITO device is lower than that of commercial ITO-based device by about $0.08 \mathrm{~V}$, which is exactly the difference in work functions. This corresponds to situation mentioned above.

The fill factor (FF) of the solar cells fabricated on commercial and RF-sputtered ITO thin films are 0.44 and 0.28 , respectively at a light intensity of $95 \mathrm{~mW} / \mathrm{cm}^{2}$ under AM 1.5 illumination at room temperature. Since FF is totally dependent on the quality of $J-V$ characteristics. For this, it is crucial to have high carrier mobility, low trap density, and negligible space charge effect. In other ways, effective collection of free charge carriers results better output power [37]. The conversion efficiencies of the above solar cell devices are 1.5 and $1.2 \%$, respectively, that is, lower for the RF-sputtered ITO case. The inferior fill factor and lower conversion efficiency of the solar cell fabricated on the RF-sputtered ITO films is due to higher sheet resistance, that is, poor conductivity $(\sigma=8.1 \times$ $\left.10^{2} \Omega^{-1} \mathrm{~cm}^{-1}\right)$. The parasitic resistive power loss also causes reduction in FF and depends mainly on series and shunt resistances. For an efficient solar cell, series resistance should be low whereas shunt resistance should be high. The series resistance $\left(R_{S}\right)$ originates from the bulk of organic layer (P3HT : PCBM blends and PEDOT : PSS), electrodes (anode ITO and cathode metals), and the contact resistance between 
the active layer and the electrode. On the other hand, the shunt or parallel resistance $\left(R_{\mathrm{sh}}\right)$ arises from the charge recombination at the donor/acceptor interface, through the cell and around the edges of the device $[38,39]$. The $R_{s}$ and $R_{\mathrm{sh}}$ have been determined from the inverse slopes of $J-V$ curve at bias voltage of over $V_{\text {oc }}$ (i.e., $J_{\text {sc }} \geq 0$ ), and zero, respectively [40]. The series resistance of identical device on commercial and RF-sputtered ITO are 55.7 and $64.3 \Omega-\mathrm{cm}^{2}$, respectively. The corresponding shunt resistance values are 325.4 and $110 \Omega-\mathrm{cm}^{2}$, respectively. The higher value of shunt resistance in commercial ITO results in negligible leakage current and so leads to higher conductivity. It may be pointed out that the commercial ITO is normally annealed at a high temperature for attaining low sheet resistance value, that is, high conductivity. The present experiment is directed towards RF sputtered ITO films for solar cells and OLED on polythene sheets, high temperature annealing is intentionally avoided.

\section{Conclusions}

The ITO thin films can be prepared by RF sputtering at a substrate temperature of $70^{\circ} \mathrm{C}$ on glass with (222) preferred orientation, grain size of $7 \mathrm{~nm}$, high optical transparency of $95 \%$ in the wavelength range of $550-650 \mathrm{~nm}$, and sheet resistance of $103 \Omega / \square$ (higher than $36 \Omega / \square$ of commercial ITO). The short-circuit current density $\left(J_{\mathrm{sc}}\right)$ and open-circuit voltage $\left(V_{\mathrm{oc}}\right)$ of the device fabricated on the RF sputtered are $7.6 \mathrm{~mA}-\mathrm{cm}^{-2}$ and $0.55 \mathrm{~V}$, respectively. The corresponding values of $J_{\mathrm{sc}}$ and $V_{\mathrm{oc}}$ are $5.2 \mathrm{~mA}-\mathrm{cm}^{-2}$ and $0.63 \mathrm{~V}$ for solar cells based on commercial ITO. The fill factor (0.28) and conversion efficiency (1.2\%) of the solar cell with RFsputtered ITO layer are smaller than those fabricated with commercial ITO (values being 0.44 and $1.5 \%$, resp.). The substantial increase in short-circuit current density of the solar cell can be attributed to smaller nanocrystallites which cause dominant light scattering at the grain boundaries towards the active layer for better light absorption. The opencircuit voltage is limited by the size effects as well as defects, responsible for trapping/accumulation of charge carriers at the anode interface, of ITO. This emphasizes the importance of the anode (ITO) surface morphology in polymer solar cells.

\section{Acknowledgment}

The financial support from DRDO and DST is duly acknowledged.

\section{References}

[1] B. Ren, X. Liu, M. Wang, and Y. Xu, "Preparation and characteristics of indium tin oxide (ITO) thin films at low temperature by r.f. magnetron sputtering," Rare Metals, vol. 25, no. 6, pp. 137-140, 2006.

[2] D. Kalhor, S. A. Ketabi, A. Ebrahimzad, and M. M. Rezaei, "Annealing effects on opto-electronic properties of thermallyevaporated ITO/Ag/ITO multilayered films for use in color filter electrodes," World Applied Sciences Journal, vol. 6, pp. 8387, 2009.

[3] A. Sharma, P. J. Hotchkiss, S. R. Marder, and B. Kippelen, "Tailoring the work function of indium tin oxide electrodes in electrophosphorescent organic light-emitting diodes," Journal of Applied Physics, vol. 105, no. 8, Article ID 084507, 6 pages, 2009.

[4] J. G. Yoon, S. W. Cho, E. Lee, and J. S. Chung, "Characteristics of indium-tin-oxide Schottky contacts to $\mathrm{ZnMgO} / \mathrm{ZnO}$ heterojunctions with band gap grading," Applied Physics Letters, vol. 95, no. 22, Article ID 222102, 3 pages, 2009.

[5] V. S. Reddy, K. Das, A. Dhar, and S. K. Ray, "The effect of substrate temperature on the properties of ITO thin films for OLED applications," Semiconductor Science and Technology, vol. 21, no. 12, pp. 1747-1752, 2006.

[6] R. G. Gordon, "Criteria for choosing transparent conductors," MRS Bulletin, vol. 25, no. 8, pp. 52-57, 2000.

[7] S. E. Shaheen, R. Radspinner, N. Peyghambarian, and G. E. Jabbour, "Fabrication of bulk heterojunction plastic solar cells by screen printing," Applied Physics Letters, vol. 79, no. 18, pp. 2996-2998, 2001.

[8] Y. Yang, Q. Huang, A. W. Metz et al., "High-performance organic light-emitting diodes using ITO anodes grown on plastic by room-temperature ion-assisted deposition," Advanced Materials, vol. 16, no. 4, pp. 321-324, 2004.

[9] Y. Hong, Z. He, N. S. Lennhoff, D. A. Banach, and J. Kanicki, "Transparent flexible plastic substrates for organic light-emitting devices," Journal of Electronic Materials, vol. 33, no. 4, pp. 312-320, 2004.

[10] Y. C. Park, Y. S. Kim, H. K. Seo, S. G. Ansari, and H. S. Shin, "ITO thin films deposited at different oxygen flow rates on Si(100) using the PEMOCVD method," Surface and Coatings Technology, vol. 161, no. 1, pp. 62-69, 2002.

[11] J. Matsuo, H. Katsumata, E. Minami, and I. Yamada, " $\mathrm{O}_{2}$ cluster ion-assisted deposition for tin-doped indium oxide films," Nuclear Instruments and Methods in Physics Research, Section B, vol. 161, pp. 952-957, 2000.

[12] J. Olivier, B. Servet, M. Vergnolle, M. Mosca, and G. Garry, "Stability/instability of conductivity and work function changes of ITO thin films, UV-irradiated in air or vacuum. Measurements by the four-probe method and by Kelvin force microscopy," Synthetic Metals, vol. 122, no. 1, pp. 87-89, 2001.

[13] E. Holmelund, B. Thestrup, J. Schou et al., "Deposition and characterization of ITO films produced by laser ablation at 355 nm," Applied Physics A, vol. 74, no. 2, pp. 147-152, 2002.

[14] V. Craciun, D. Craciun, X. Wang, T. J. Anderson, and R. K. Singh, "Transparent and conducting indium tin oxide thin films grown by pulsed laser deposition at low temperatures," Journal of Optoelectronics and Advanced Materials, vol. 5, no. 2, pp. 401-408, 2003.

[15] K. Nishio, T. Sei, and T. Tsuchiya, "Preparation and electrical properties of ITO thin films by dip-coating process," Journal of Materials Science, vol. 31, no. 7, pp. 1761-1766, 1996.

[16] D. Kim, Y. Han, J.-S. Cho, and S.-K. Koh, "Low temperature deposition of ITO thin films by ion beam sputtering," Thin Solid Films, vol. 377-378, pp. 81-86, 2000.

[17] K. H. Kim, K. Choi, E. S. Choi, J. H. Hwang, and J. T. Hwang, "Indium tin oxide thin films deposited by RF-magnetron sputtering for organic electro-luminescence devices," Journal of Ceramic Processing Research, vol. 4, no. 2, pp. 96-100, 2003.

[18] I. Baía, M. Quintela, L. Mendes, P. Nunes, and R. Martins, "Performances exhibited by large area ITO layers produced by r.f. magnetron sputtering," Thin Solid Films, vol. 337, no. 1-2, pp. 171-175, 1999. 
[19] A. Subrahmanyam and N. Balasubramanian, "Studies of the photovoltaic behaviour of indium tin oxide (ITO)/silicon junctions prepared by the reactive thermal evaporation technique," Semiconductor Science and Technology, vol. 7, no. 3, article 07, pp. 324-327, 1992.

[20] M. Nisha, S. Anusha, A. Antony, R. Manoj, and M. K. Jayaraj, "Effect of substrate temperature on the growth of ITO thin films," Applied Surface Science, vol. 252, no. 5, pp. 1430-1435, 2005.

[21] N. Manavizadeh, F. A. Boroumand, E. Asl-Soleimani et al., "Influence of substrates on the structural and morphological properties of RF sputtered ITO thin films for photovoltaic application," Thin Solid Films, vol. 517, no. 7, pp. 2324-2327, 2009.

[22] C. V. R. Vasant Kumar and A. Mansingh, "Effect of targetsubstrate distance on the growth and properties of rf-sputtered indium tin oxide films," Journal of Applied Physics, vol. 65, no. 3, pp. 1270-1280, 1989.

[23] B. D. Cullity, Elements of X-Ray Diffractions, Addison-Wesley, Reading, Mass, USA, 1959.

[24] T. S. Sathiaraj, "Effect of annealing on the structural, optical and electrical properties of ITO films by RF sputtering under low vacuum level," Microelectronics Journal, vol. 39, no. 12, pp. 1444-1451, 2008.

[25] R. Vinodkumar, K. J. Lethy, D. Beena et al., "Effect of ITO buffer layers on the structural, optical and electrical properties of $\mathrm{ZnO}$ multilayer thin films prepared by pulsed laser deposition technique," Solar Energy Materials and Solar Cells, vol. 94, no. 1, pp. 68-74, 2010.

[26] A. K. Kulkarni, K. H. Schulz, T. S. Lim, and M. Khan, "Dependence of the sheet resistance of indium-tin-oxide thin films on grain size and grain orientation determined from Xray diffraction techniques," Thin Solid Films, vol. 345, no. 2, pp. 273-277, 1999.

[27] P. Thilakan, C. Minarini, S. Loreti, and E. Terzini, "Investigations on the crystallisation properties of RF magnetron sputtered indium tin oxide thin films," Thin Solid Films, vol. 388, no. 1-2, pp. 34-40, 2001.

[28] J. C. Slater, "Barrier theory of the photoconductivity of lead sulfide," Physical Review, vol. 103, no. 6, pp. 1631-1644, 1956.

[29] T. L. Benanti and D. Venkataraman, "Organic solar cells: an overview focusing on active layer morphology," Photosynthesis Research, vol. 87, no. 1, pp. 73-81, 2006.

[30] L. A. Dobrzanski, L. Wosinska, B. Dolzanska, and A. Drygała, "Comparison of electrical characteristics of silicon solar cells," Journal of Achievements in Materials and Manufacturing Engineering, vol. 18, pp. 215-218, 2006.

[31] J. D. Servaites, M. A. Ratner, and T. J. Marks, "Practical efficiency limits in organic photovoltaic cells: functional dependence of fill factor and external quantum efficiency," Applied Physics Letters, vol. 95, no. 16, Article ID 163302, 3 pages, 2009.

[32] R. Apetz and M. P. B. Van Bruggen, "Transparent alumina: a light-scattering model," Journal of the American Ceramic Society, vol. 86, no. 3, pp. 480-486, 2003.

[33] V. Dimitrov and S. Sakka, "Linear and nonlinear optical properties of simple oxides. II," Journal of Applied Physics, vol. 79, no. 3, pp. 1741-1745, 1996.

[34] C. Y. Kwong, A. B. Djurišić, P. C. Chui, and W. K. Chan, "CuPc/C60 solar cells-influence of the indium tin oxide substrate and device architecture on the solar cell performance," Japanese Journal of Applied Physics, Part 1, vol. 43, no. 4, pp. 1305-1311, 2004.
[35] V. D. Mihailetchi, P. W. M. Blom, J. C. Hummelen, and M. T. Rispens, "Cathode dependence of the open-circuit voltage of polymer:fullerene bulk heterojunction solar cells," Journal of Applied Physics, vol. 94, no. 10, pp. 6849-6854, 2003.

[36] C. J. Brabec, N. S. Sariciftci, and J. C. Hummelen, "Plastic solar cells," Advanced Funtional Materials, vol. 11, no. 1, pp. 15-26, 2001.

[37] A. Gadisa, F. Zhang, D. Sharma, M. Svensson, M. R. Andersson, and O. Inganäs, "Improvements of fill factor in solar cells based on blends of polyfluorene copolymers as electron donors," Thin Solid Films, vol. 515, no. 5, pp. 3126-3131, 2007.

[38] B. Muhsin, J. Renz, K. H. Drüe, G. Gobsch, and H. Hoppe, "Influence of polymer solar cell geometry on series resistance and device efficiency," Physica Status Solidi (A), vol. 206, no. 12, pp. 2771-2774, 2009.

[39] J. Nelson, The Physics of Solar Cell, Imperial College Press, London, UK, 2003.

[40] M. Chegaar, Z. Ouennoughi, F. Guechi, and H. Langueur, "Determination of solar cells parameters under illuminated conditions," The Journal of Electron Device, vol. 2, pp. 17-21, 2003. 


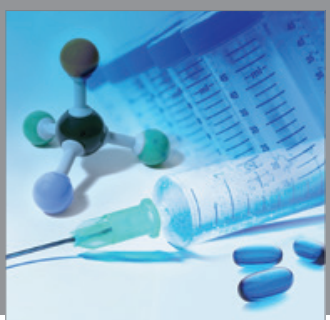

International Journal of

Medicinal Chemistry

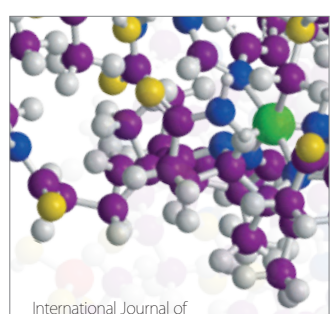

Carbohydrate Chemistry

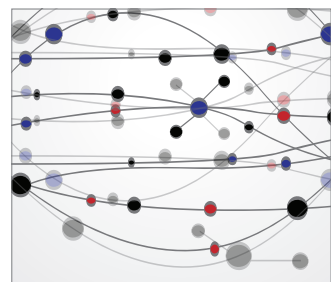

The Scientific World Journal
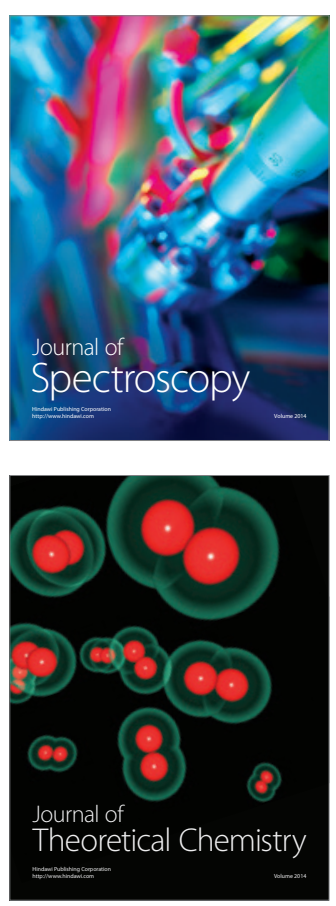
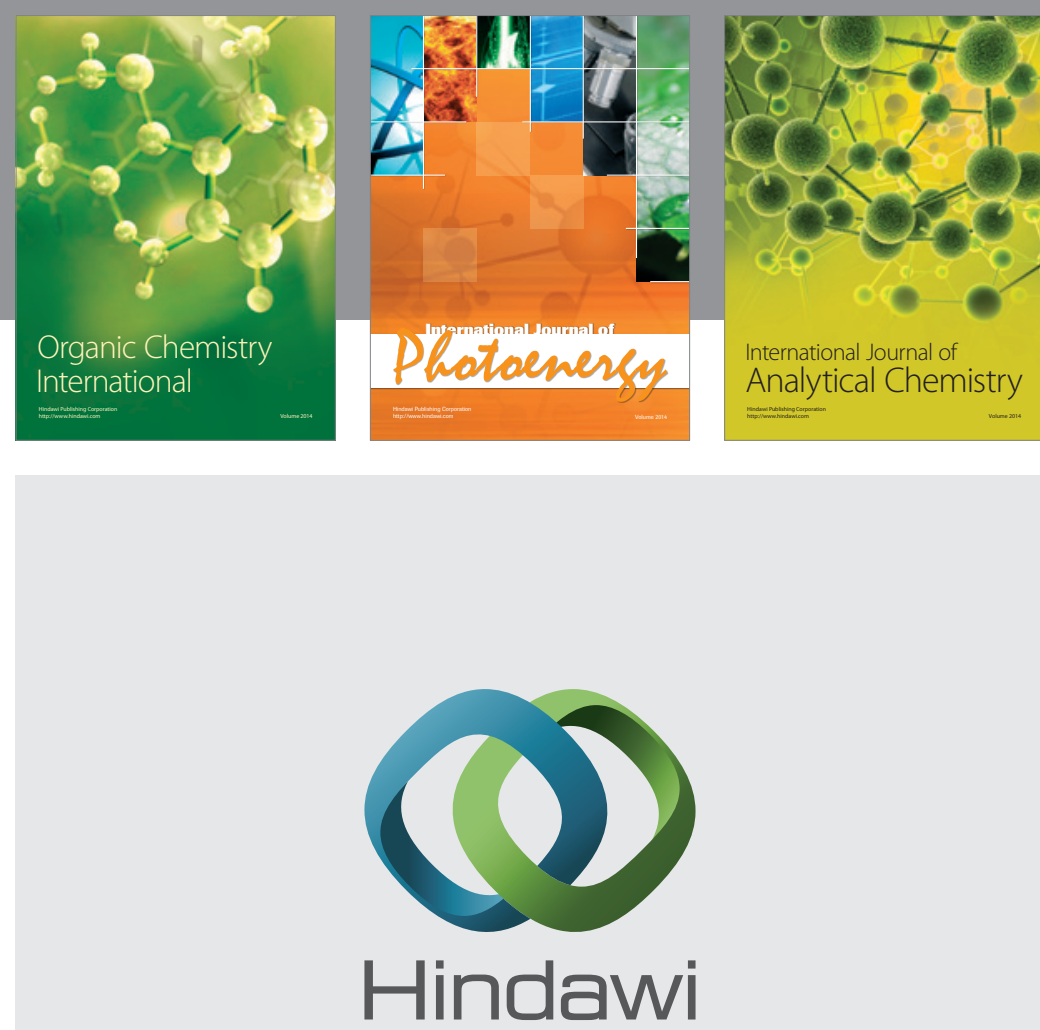

Submit your manuscripts at

http://www.hindawi.com
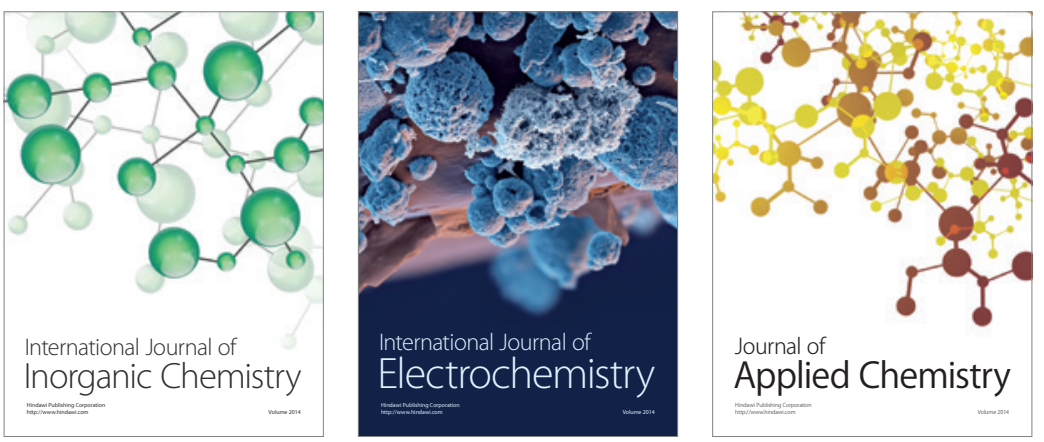

Journal of

Applied Chemistry
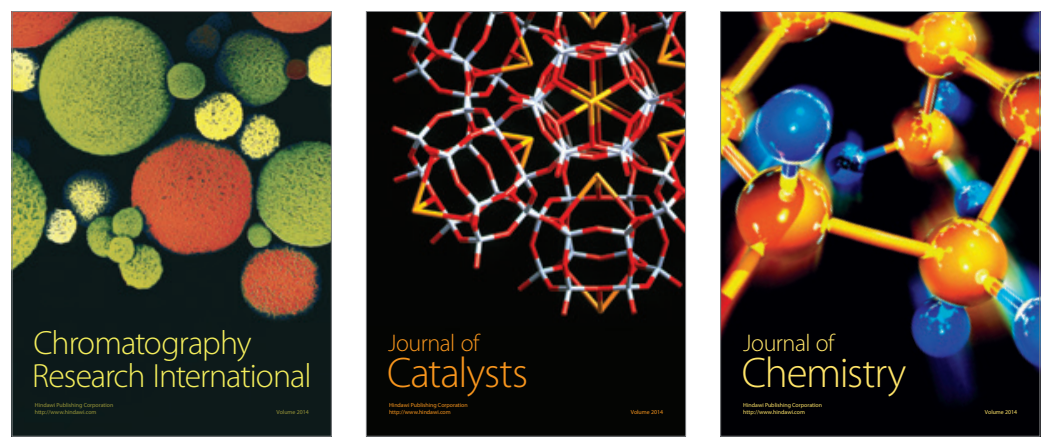
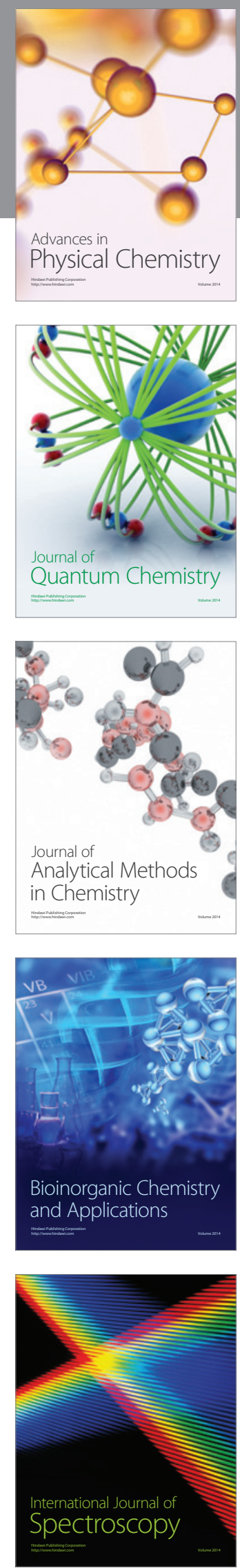